\title{
Exploring Possibilities of Upgrading Per Capita Municipal Solid Waste Estimation Methods in India
}

\author{
Rohit V Bhagwat ${ }^{1 *}$ and Dilip B Boralkar ${ }^{2}$ \\ ${ }^{1}$ Ph. D Student,Department of Environmental Science, Savitribai Phule Pune University, Ganeshkhind, Pune - 411007, Maharashtra, India \\ ${ }^{2}$ Adjunct Professor,Department of Environmental Science, Savitribai Phule Pune University, Ganeshkhind, Pune - 411007, Maharashtra, India
}

Received: December 21, 2017; Accepted: December 27, 2017 ; Published: February 08, 2018

*Corresponding author: Ph.D Student,Department of Environmental Science, Savitribai Phule Pune University, Ganeshkhind, Pune - 411007, Maharashtra, India, Tel: +91-9923970437, E-mail: rvbhagwat@gmail.com

\begin{abstract}
India is one of the fastest growing economies of the world, which has reflected in the steep infrastructural growth being observed in most of the Indian cities. However, the evolution of urban waste management system has not matched the fast pace of urbanization. The inefficiency of solid waste management systems could be attributed to unreliable and inaccurate estimation of municipal solid waste (MSW) generation, obtained due to lack of data on population dynamics (unpredictable rural urban migrations) and incomplete information on bulk waste from the informal sector.
\end{abstract}

As per rules published by MoEF, 2000 and MoEF \& CC, 2016, it is expected that all the urban local bodies should comply with the rules and manage the waste as suggested, however none of the urban local bodies managed to comply as of now. One of the reasons being inappropriate estimation of MSW and therefore, in the present study, using a case study of Pune City, the 8th largest metro city in India, we tried to highlight the inconsistency and unreliability of currently used methods for per capita estimation of MSW generation. We have also analysed available data to see how integration of informal waste sector could help in predicting more accurate estimates.

We suggest derivation of more robust, scientific and standardised method at national level and integration of informal sector in to the mainstream waste management system, which will help municipal authorities and policy makers in India to formulate effective strategies for value recovery form wastes and protection of environment.

Keywords: Municipal Solid Waste; Per Capita; Estimations; Informal Sector; Planning;

\section{Abbreviations}

ANN

Artificial Neural Network

СРCB

Central Pollution Control Board

CPHEEO

Central Public Health and Environmental Engineering Organization

GIS Geographical Information System

GIPE Gokhale Institute of Politics and Economics

GNI Gross National Income

Kg Kilograms
MoEF\& CC

Ministry of Environment, Forest \& Climate Change

MSW Municipal Solid Waste

PMC Pune Municipal Corporation

SPCB State Pollution Control Board

TPD Tons per day

ULB Urban Local Body

\section{Introduction}

India has been experiencing rapid urbanisation due to migration of people to urban areas seeking jobs, better lifestyles, etc. Over 1.21 billion of population in India, the urbanisation in the country has increased to from $27.8 \%$ in 2001 to $31.2 \%$ of the total population by year 2011 that is about 377 million people live in 7,935 urban areas with 4041 municipal authorities and is expected to rise to $50 \%$ by year 2050 [1,2-4]. The generation of waste is influenced by a number of factors such as population, purchasing power, standard of living, commercial activities, seasons and Gross National Income (GNI) [2,5-7].

Even though Municipal Solid Waste (MSW) management is an essential function of the urban local body (ULB), it is a poorly rendered service resulting in environmental degradation and causing negative impacts on human health[8]. The ULBs are not able to cope up with the rapid urban growth and MSW infrastructure development. The reasons for under performance such as institutional weakness and improper choice of technology, etc.are reported by CPHEEO Planning of infrastructure, use of technology and provision of other related support systems is driven by accurate data of generation of waste on a "per person per day basis" and the composition of the waste[9, 10]. Therefore, per capita waste generation and composition serve as vital indictors of environmental pressure. Data on Municipal Solid Waste (MSW) generation can contribute to better waste management practices. This data can further be used for comparative analysis of waste generation intensities between cities [6].

Waste management system in India is multimodal (figure. 1) with a combination of formal sector, informal sector and 
other actors (e.g. generators) is involved and is an integral part of the waste management system. The formal system involves, service providers such as ULBs collecting bulk of the MSW [8]. The informal sector (waste-pickers and itinerant buyers) mainly engages in either in free collection of recyclables from the garbage dumps and municipal waste bins or buying scrap from individual properties, whereas generators (self-disposal) sometimes either throw the waste on the streets and open water bodies or burn it out in the open. [11, 5]

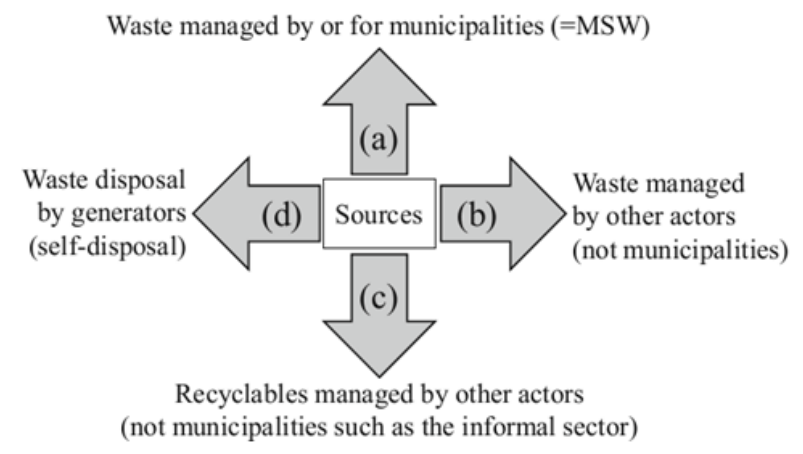

Figure 1: Conceptual diagram of multimodal MSW management system [5]
Ministry of Environment, Forest \& Climate Change (MoEF\& $\mathrm{CC}$ ) requires the ULBs to integrate the informal sector in to the mainstream so that a robust waste management system can be established however none of the ULBs have complied as of now [12]. Further integration of formal and informal sectors is essential waste infrastructure planning to cope up with the requirements. Indian MSW management system currently lacks a standardised method to estimate waste collected by informal sectorand other actors (Figure.2) impacting reliability of the data; additionally, the data reliability is also hampered by lack of trained workforce, infrastructure including equipment and lower collection efficiencies, etc. [3,5].

Currently, in India random sampling method is used to estimate garbage generation, where representative samples are taken based on the land-use viz. residential, commercial, and institutional, etc. Waste quantity and quality data is gathered and extrapolated to the entire ULB. Per capita waste generation rates are calculated by dividing the waste quantity data for the entire ULB by the population. [13] This sampling methodology provides data only for one point of time which is highly site specific and thus has a drawback, of not being trulyrepresentative. [10]

In order to highlight the deficiencies in the current estimation methods and exploring possibilities of improvisation in exiting MSW estimation methods; 4 different methods were used in the

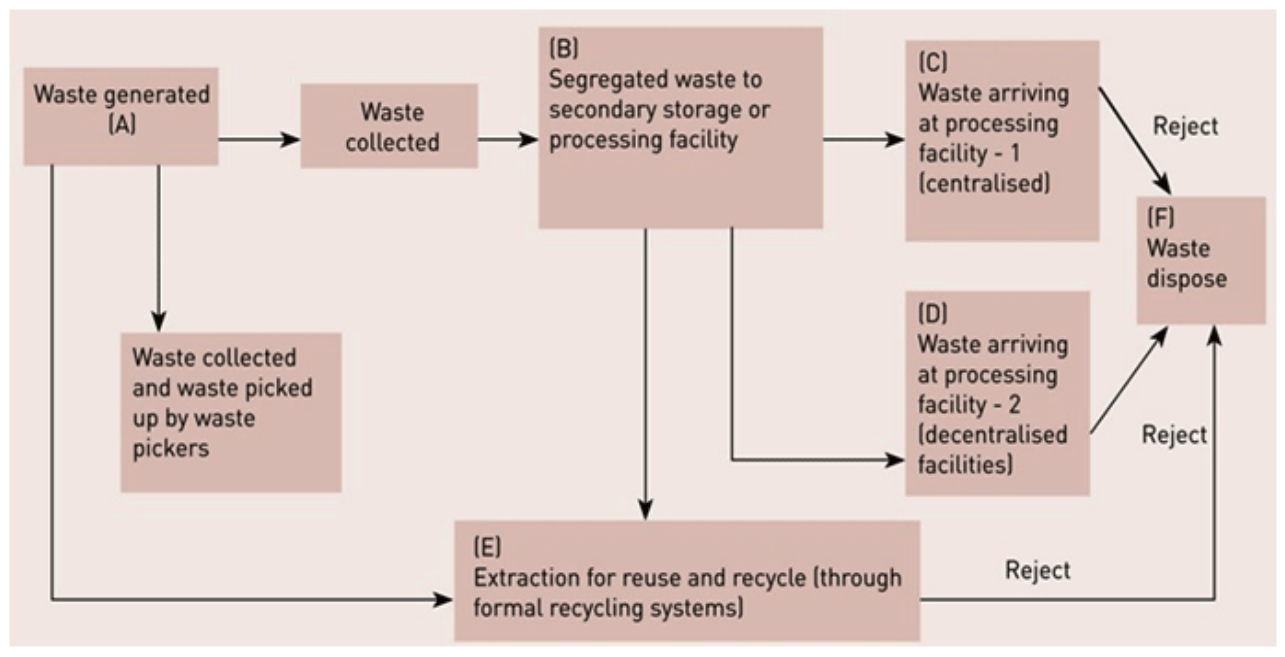

Figure 2: Schematic representation of waste estimation in India showing exclusion of informal sector data [13]

context of Pune city as a case study. Pune is the 8th largest city in India with population of about 0.33 million in 2011, expanding to just over 4 million in 2016 due to dynamic academic, cultural and economic centre [14]. The city expects a net in-migration of 600,000 in 2021 - 2026 from 370,000 in 1991-2001. [22] Apart from the issues of population and net in-migration, the ULB and the regulator (State Pollution Control Board) have been reporting highly inconsistent and discrepant MSW generation data (Table 1) which has severely influenced the overall planning of waste management systems in the city. Therefore, Pune seemed a suitable case to apply these 4 methods.
Within the scope of this study, the contribution from formal, informal sector were considered. Through these data; per capita waste generation was estimated and compared with different methods to show level of discrepancy and low reliability of the existing data sets. The outcome of this work suggestsa need for a scientific methodology to estimate accurate waste related data. This study is one of its kinds in the country where a comparative analysis of more than one method is undertaken to find reliability of the existing methods while exploring other methods which may give more reliable data on waste quantities. 
Table 1: MSW generation for Pune City reported by State Pollution Control Board (SPCB) \& Pune Municipal Corporation (PMC)

\begin{tabular}{|l|l|l|}
\hline Year & MSW generation (TPD) ${ }^{*}$ & MSW generation (TPD) \\
\hline $2009-10$ & NA & $1300-1400$ \\
\hline $2010-11$ & 750 & $1300-1400$ \\
\hline $2011-12$ & 750 & 1400 \\
\hline $2012-13$ & 1600 & $1300-1400^{s}$ \\
\hline $2013-14$ & 1600 & $1500-1600$ \\
\hline $2014-15$ & 2100 & $1600-1700$ \\
\hline $2015-16$ & 1700 & $1600-1700$ \\
\hline $2016-17$ & 1700 & 1700 \\
\hline
\end{tabular}

Legend: NA - not available; TPD - tons per day; ${ }^{\text {PPune City Sanitation }}$ Plan, 2012

Source: $\left[15-21^{*}, 23-29^{\#}\right]$

\section{Materials and Methods}

\section{Population Estimation of Pune City}

The population of the city was estimated for year 2016 at about 4 million; using population census data, 2011 and annual population growth rate (Alternative I) suggested by Gokhale Institute of Politics and Economics (GIPE). [14,22]

\section{Estimation of MSW Generated Within the City}

We analysed the data from 2015 for estimation of per capita MSW. However, the waste that was burnt, garbage thrown in open waters and uncollected waste were not considered as these quantities are difficult to estimate. The generation of MSW within Pune city was estimated as described below.

\section{Method 1}

Annually, the State Pollution Control Board (SPCB) as a regulator gathers MSW data from ULB sin this case Pune Municipal Corporation (PMC), which is then submitted to the Central Pollution Control Board (CPCB) as compliance towards Solid Waste Management Rules, 2000 in the form of 'Annual Report on Implementation' $[23,30]$. The data represented in this work is extracted from annual reports prepared by SPCB

\section{Method 2}

MSW data was collected from 12 municipal ward offices (out of 15) for the year 2015. These 12 ward offices cover more than 737,980 properties across the city. Waste collection data reported by ward office was at waste collection efficiency of about $80 \%$. The data was then analysed, processed and extrapolated for remaining 3 ward offices for year 2015. An annual per capita MSW generation for year 2016 has been calculated using annual per capita waste generation increase rate of $1.33 \%$. [2, 6]

\section{Method 3}

MSW data was collected as explained in Method 2. Indian waste management system has no formal way of accounting the waste (mostly recyclables) collected by the informal sector (waste pickers, itinerant buyers) and therefore the information on approximate waste quantities collected by waste pickers was recorded by personal communication. As per PMC contract with SWaCH during 2016, there were about 9500 waste pickers. Although data from informal sectorare not authenticated and may reflect unreliability, however it offers a comparison between different data sets collected.

\section{Method 4}

This technique is a combination of methods suggested by Kawai and Tasaki to represent the formal data integrated with the waste data from informal sector (data collection as informed in method 3 [5]. This methodology uses 2 equations as described Equation. (1) and Equation. (2) for data on garbage. This involves vehicular (e.g. Push carts, Refuse trucks) data such as number of vehicles, capacity of the vehicle, frequency of trips etc. which was collected from PMC for 3 consecutive months along with waste characteristics such as waste density. Using this data, the estimates of waste generation in the city were calculated.

Method 4A - W = c * $\mathrm{v}^{*} \mathrm{~d} * \mathrm{t} * \mathrm{l} * 365 \quad$... Equation. (1)

$\mathrm{W}=$ annual MSW generation amount (tons per year)

$\mathrm{c}=$ average capacity of a waste-hauling truck $\left(\mathrm{m}^{3}\right.$ per truck)

$\mathrm{v}=$ average loading volume ratio of a truck

$\mathrm{d}=$ average density of MSW loaded on truck (tons per $\mathrm{m}^{3}$ )

$\mathrm{t}=$ average number of trips per truck (frequency of trips per day) $\mathrm{l}=$ average number of operating trucks (number of trucks per day)

Method 4B $-\mathrm{W}={ }_{\mathrm{J}=1} \sum_{\mathrm{i}=1}^{365} \sum^{\mathrm{m}}\left(\mathrm{ci}^{*} \mathrm{vi}^{*} \mathrm{di} * \mathrm{tij}\right) \quad$... Equation. (2) $\mathrm{W}=$ annual MSW generation amount (tons per year)

$\mathrm{m}=$ total no of trucks

$\mathrm{ci}=$ average capacity of a waste-hauling truck $\left(\mathrm{m}^{3}\right.$ per truck $)$

$\mathrm{vi}=$ average loading volume ratio of a truck

$\mathrm{di}=$ average density of MSW loaded on truck (tons per $\mathrm{m}^{3}$ )

tij = number of trips by truck $\mathrm{i}$ on day $\mathrm{j}$ (frequency of trips per day)

\section{Results and Discussion}

Overall, it can be observed that the city does not have a robust and scientific methodology to estimate per day MSW generation in city. The annual reporting of MSW generation in city done by the PMC and SPCB is mostly ad-hoc, inconsistent and lacks reliability. The SPCB as a regulator and scientific entity fails to collect \& verify appropriate MSW data and advise PMC accordingly. SPCB also fails to prepare a comprehensive plan for prevention and abatement of pollution caused due to improper MSW management. Furthermore, it did not consider the contribution from the informal sector and hence the data published is unreliable. (table 2 \& figure. 3 ) 


\begin{tabular}{|c|c|c|c|c|c|c|}
\hline Sr. & Description & Method 1 & Method 2 & Method 3 & Method 4 - A & Method 4 - B \\
\hline 2 & $\begin{array}{c}\text { Estimated MSW } \\
\text { generation of Pune city } \\
2016 \text { (TPD) }\end{array}$ & 1700 & 1756.78 & 1756.78 & 1962.85 & 1985.33 \\
\hline 3 & $\begin{array}{l}\text { Recyclables collected } \\
\text { by informal sector } \\
\text { (TPD) }\end{array}$ & $\begin{array}{l}\text { Not considered } \\
\text { by MPCB }\end{array}$ & $\begin{array}{l}\text { Not considered by } \\
\text { PMC ward offices }\end{array}$ & 475 & 475 & 475 \\
\hline 4 & $\begin{array}{l}\text { Total MSW generated } \\
\text { In Pune city (TPD) }\end{array}$ & 1700 & 1756.78 & 2231.78 & 2437.85 & 2460.33 \\
\hline 5 & $\begin{array}{l}\text { MSW generation (kg/ } \\
\text { capita/day) }\end{array}$ & 0.42 & 0.44 & 0.56 & 0.6 & 0.61 \\
\hline
\end{tabular}

Legend: TPD: Tons per day

The waste data reported in method 2, varies by about $3 \%$ even though the SPCB gathers data from PMC on an annual basis. The reason of this deviation could not be found out. The ward office data reported in method $2 \& 3$ is based on offline vehicle weighing records of waste transportation across the city. Method 2 does not include the data from informal sector due to absence of formal mechanism of integrating informal sector dataand hence cannot be relied upon. Upon integrating informal sector data; Method 3 records over 27\% higher per capita waste generation in the city.

Method 4 is more elaborative and includes daily waste collection data based on the types of vehicles and their carrying capacity. It also considers parameters such as vehicular trip frequency, loading capacity of the vehicle and the waste density, etc. This data coupled with the informal sector data provides more comprehensive view on the MSW estimates in the city. Method 4 (A \& B respectively) provides more scientific basis of waste estimations and can be relied upon. It reports about $44 \%$ higher waste generation than that of estimates provided by the Method 1 and about 40\% higher than that of Method 2. Further, Method 4 (A \& B respectively) reports about 10\% higher waste generation than that of method 3 . This suggests that the offline vehicular data available with the ward offices is not entirely correct and need to be reviewed for accuracy and consistency.

The deviation in the outcomes of Method 4A \& 4B is about $0.92 \%$ and is minor. This deviation is caused due to difference in parameters, where method $4 \mathrm{~B}$ focuses more on the data from each hauling truck whereas Method 4A is an overall method of using waste transportation by trucks. The results suggest that unreliable data sets have hampered the overall waste planning and management in Pune city. Managing about $40 \%$ higher waste quantities pose a difficult task for the municipal corporation of the city.
Waste estimations are highly influenced by the urbanisation and net in- migration which the city failed to acknowledge over the years. Estimations of waste need to be coupled with the urban development and rise in city's population, whereas collection efficiencies can be correlated with the population densities in urban areas. Currently, Pune uses random sampling method to quantify municipal waste which is unscientific and unreliable as sample obtained from certain sampling location may differ in a same day if the repeat sample is taken at the same location.

The city can make use of GIS analysis or a scalogram analysis and spatial linkages to provide a better understanding of settlements and services provision within different zones of urban areas. Researchers from countries like USA and Iran have used other theoretical and modelling methods such as system dynamics simulation tools and Artificial Neural Network (ANN) to forecast the trends of municipal solid waste generation in cities like San Antonio, Texas and Mashhad in Iran respectively. [31, 32] The above methods can further be strengthened with the help of stratified, purposive and direct sampling techniques which would provide more reliable data. The sampling method could also include socio-economic aspects such as high, middle and low income groups to verify and support the waste estimation quantities. A data verification methodology should also be developed. Application of smart solutionfor online data reporting system such as centrally located facilitation centre should be developed so that manual errors can be avoided and real time information is recorded.

In order to achieve waste management priority goals set under various regulations, plans and programmes such as Smart City Mission, Swachh Bharat Mission; it is essential to ensure capacity building of the workforce, upgradation of various subsystems, and availability of funds along with integration of policy with scientific methods, technology, enforcement and governance. 


\section{Conclusion}

With rapid population growth and urbanisation, Indian waste management system is facing challenges. Integration of contribution from all sections of the multimodal waste management system that is formal and informal is essential for overall waste management planning. However, current planning procedures lack such integration and scientific assessment making planning and implementation difficult. Application of 4 different waste estimation methods for Pune city suggests that inconsistent and unreliable data sets pose more difficulties in waste planning process resulting in environmental degradation and impact on public health. Incomplete information impacts negatively on services provision and infrastructure capabilities. Therefore, an integration of informal sector in to mainstream waste management system is also important. A national level scientific and standardised method for gathering accurate and reliable MSW data is vital. Reporting of data on waste generation is largely rudimentary and requires a unified mechanism across the country and to be monitored periodically to check for inconsistencies.Unless and until scientific and reliable methods are adopted, India will not be able to achieve set targets of municipal waste management.

\section{Acknowledgement}

Authors would like to thank Professor Nitin Karmalkar, Vice Chancellor, Savitribai Phule Pune University, Professor Suresh Gosavi, Head, Department of Environmental Sciences, Savitribai Phule Pune University and Professor Venkat Gunale for their continuous encouragement and support.

\section{Conflict of Interest}

The authors declare that they have no competing interests.

\section{References}

1. Rural-Urban Distribution. Trends in Urbanization 4th Ch. 2011; 2(2):1-57

2. Ghosh S K. Sustainable SWM in developing countries focusing on faster growing economies, India and China. International Conference on Solid Waste Management, 5IconSWM 2015. Procedia Environmental Sciences. 2016;35: 176-184.

3. Planning Commission. Report of the Task Force on Waste to Energy (Volume I): In the context of Integrated MSW Management. 2014;

4. Talyan V, Dahiya R P, Sreekrishnan T R. State of municipal solid waste management in Delhi, the capital of India. Waste Management. 2008;28(7): 1276-1287. Doi: org/10.1016/j.wasman.2007.05.017

5. Kawai K and Tasaki T. Revisiting estimates of municipal solid waste generation per capita and their reliability. J Mater Cycles Waste Manag. 2016;18(1): 1-13.

6. Sebastian R M and Alappat B. Thermal properties of Indian municipal solid waste over the past, present and future years and its effect on thermal waste to energy facilities. Civil Engineering and Urban Planning: An International Journal. 2016;3(2): 97-106 Doi:10.5121/ civej.2016.3208

7. World Energy Council (WEC). World Energy Resources: Waste to Energy. 2016;
8. Government of India (GoI). The Constitution (Seventy Fourth Amendment) Act 1992. Enforcement: 1-6-1993 [S.0. 346(E), dated 1-6-1993]. 1992;

9. Advisory on improving Municipal Solid Waste Management Services. Central Public Health and Environmental Engineering Organization (CPHEEO). 2013;

10. Tchobanoglous G and Kreith F. Handbook of Solid Waste Management, 2ndedition. McGRAW - HILL Publication. 2002.

11. Chikarmane $\mathrm{P}$ and Narayan L. Rising from the Waste- Organising Waste-pickers in India, Thailand and the Philippines. Committee for Asian Women (CAW). 2009;

12. Ministry of Environment, Forest \& Climate Change (MoEF\& CC) Solid Waste Management (SWM) Rules, 2016;

13. Municipal Solid Waste Management Manual Part II: The manual. Ministry of Urban Development (MoUD). Central Public Health and Environmental Engineering Organisation (CPHEEO). 2016;

14. Primary Census Abstract Data. 2015

15. Pune Municipal Corporation (PMC). Environment Status Report, Pune City for year 2009-2010. 2010;

16. Pune Municipal Corporation (PMC). Environment Status Report, Pune City for year 2010-2011. 2011;

17. Pune Municipal Corporation (PMC). Environment Status Report, Pune City for year 2011-2012. 2012;

18. Pune Municipal Corporation (PMC). Environment Status Report, Pune City for year 2013-2014. 2014;

19. Pune Municipal Corporation (PMC). Environment Status Report, Pune City for year 2014-2015. 2015;

20. Pune Municipal Corporation (PMC). Environment Status Report, Pune City for year 2015-2016. 2016;

21. Pune Municipal Corporation (PMC). Environment Status Report, Pune City for year 2016-2017. 2017;

22.Gokhale Institute of Politics and Economics (GIPE).Demographic Projections for Pune Municipal Corporation, 2001-2027. 2009;

23. Maharashtra Pollution Control Board (MPCB). Annual Report on Implementation of Municipal Solid Waste (Management \& Handling) Rules, 2000, for the State of Maharashtra for the years 2010-2011. 2011;

24. Maharashtra Pollution Control Board (MPCB). Annual Report on Implementation of Municipal Solid Waste (Management \& Handling) Rules, 2000, for the State of Maharashtra for the years 2011-2012. 2012;

25. Maharashtra Pollution Control Board (MPCB). Annual Report on Implementation of Municipal Solid Waste (Management \& Handling) Rules, 2000, for the State of Maharashtra for the years 2012-2013. 2013;

26. Maharashtra Pollution Control Board (MPCB).Annual Report on Implementation of Municipal Solid Waste (Management \& Handling) Rules, 2000, for the State of Maharashtra for the years 2013-2014. 2014;

27. Maharashtra Pollution Control Board (MPCB).Annual Report on Implementation of Municipal Solid Waste (Management \& Handling) Rules, 2000, for the State of Maharashtra for the years 2014-2015. 2015; 
28. Maharashtra Pollution Control Board (MPCB). Annual Report on Implementation of Municipal Solid Waste (Management \& Handling) Rules, 2000, for the State of Maharashtra for the years 2015-2016. 2016;

29. Maharashtra Pollution Control Board (MPCB).Annual Report on Implementation of Municipal Solid Waste (Management \& Handling) Rules, 2000, for the State of Maharashtra for the years 2016-2017. 2017;
30. Ministry of Environment and Forest (MoEF).Municipal Solid Wastes (Management and Handling) Rules, 2000. 2000;

31. Dyson B and Chang N B. Forecasting municipal solid waste generation in a fast-growing urban region with system dynamics modeling. Waste Management. 2005;25(7): 669-679. Doi: org/10.1016/j. wasman.2004.10.005

32. Jalili Ghazi Zade M and Noori R. Prediction of Municipal Solid Waste Generation by Use of Artificial Neural Network: A Case Study of Mashhad. Int J Environ. Res. 2008;2(1): 13-22. 